\title{
Who Is Responsible for Disinformation? European Approaches to Social Platforms' Accountability in the Post-Truth Era
}

Article in American Behavioral Scientist · February 2021

DOI: $10.1177 / 0002764221989784$

CITATION

1

2 authors:
READS

115

\section{Emiliana De Blasio}

LUISS Guido Carli, Libera Università Internazionale degl. . 32 PUBLICATIONS 139 CITATIONS

SEE PROFILE

Donatella Selva

LUISS Guido Carli, Libera Università Internazionale degl... 14 PUBLICATIONS 313 CITATIONS

SEE PROFILE

Some of the authors of this publication are also working on these related projects:

Observatory on Open Government across Europe View project

Media Studies View project 


\section{Who Is Responsible for Disinformation? European Approaches to Social Platforms' Accountability in the Post-Truth Era}

American Behavioral Scientist

(C) 202I SAGE Publications Article reuse guidelines: sagepub.com/journals-permissions DOI: $10.1177 / 0002764221989784$ journals.sagepub.com/home/abs

@SAGE

\title{
Emiliana De Blasio' and Donatella Selva ${ }^{2}$
}

\begin{abstract}
This article examines counterdisinformation policies to investigate how European countries are shaping the meaning and boundaries of social platforms' accountability. We describe the cultural determinants of social platforms' accountability through a content analysis technique that considered principles, actors, and instruments, resulting in four models of social platform accountability: accountability set by law, codecided accountability, regulated self-regulation, and pure self-regulation. Our results suggest that most of the II countries in this study maintain specific positions on the role of digital media in society. At the same time, some patterns of convergence were evident: the weakening of State control in favor of freedom of information; the enhancement of transparency in social platforms' politics-related activities as a guiding principle to ensure public monitoring; and the standardization of a multistakeholder model of coregulation. The article also focuses on the technological dimension of social platform accountability, enabling us to recognize the degree to which different models rely on algorithms. It then problematizes the limitations and risks of social platforms' accountability.
\end{abstract}

\section{Keywords}

disinformation, Europe, coregulation, self-regulation, multistakeholderism, algorithms

\footnotetext{
'LUISS University, Roma, Lazio, Italy

${ }^{2}$ University of Tuscia, Viterbo, Lazio, Italy

Corresponding Author:

Donatella Selva, Department of Economy, Engineering, Society and Enterprise, Tuscia University, Viterbo 01100 , Italy.

Email: donatella.selva@unitus.it
} 


\section{Introduction}

With the emergence of fake news and disinformation, the debate around social platforms' accountability (SPA) has pushed governments to react. Some countries are demanding that social platforms put in place mechanisms to detect and marginalize manipulative content using algorithms and artificial intelligence. This indicates a shift in the responsibility for disinformation from journalistic sources to the sociotechnological outlets through which disinformation spreads.

This article compares how countries addressed disinformation on social platforms prior to the infodemic surrounding Covid-19, which has been a watershed moment in terms of public awareness of disinformation and its salience in the political agenda. The study undertakes a comparative analysis to highlight whether and to what extent European countries have maintained a fragmented approach to media accountability or whether they have instead converged on a specific set of features. This study focuses on the technological dimension of SPA, distinguishing various platforms' reliance on automatization, algorithms, and datafication. This approach offers two main contributions to the literature on SPA: first, it outlines four models currently employed in the European context; second, it problematizes the relationship between the rule of law and algorithms in shaping SPA by highlighting its efficacy, limitations, and risks.

\section{European Models of Media Accountability: Principles, Main Actors, and Instruments}

Media accountability can be defined as those "voluntary or involuntary processes by which the media answer directly or indirectly to their society for the quality and/or consequences of publication" (McQuail, 2005, p. 207). As such, media accountability is part of interinstitutional accountability, a dimension that influences the quality of democracy (Morlino, 2012). At the same time, media accountability also involves the relationship between media and their publics, as the latter can hold media directly accountable without the intermediation of public institutions (McQuail, 2005).

Given the complexity of the models proposed in the literature (see for instance Hallin \& Mancini, 2004), we relied on three specific elements to sketch the main differences among media accountability models in Europe:

a. Principles of media legislation, articulated alongside two ideological axes (Eberwein et al., 2011; Price et al., 2015). The first axis concerns the relationship between the State and media companies, which ranges from State control to freedom-of-information models, with an intermediate stage of controlled pluralism (Christians et al., 2009; Siebert et al., 1963). The second axis distinguishes systems driven by the principle of transparency (i.e., practices intended to control media activities "behind the scenes," such as ownership, financing, and production) from those led by the principle of responsiveness (i.e., practices intended to highlight the relationship between media and their publics in a framework of media as a public service; Donders, 2012; Lowe, 2009). 
b. Main actors, identifying the role played by public institutions, media companies, professionals, and the public, enabling distinction among assigned, contracted, or self-imposed responsibilities (Bruijn \& Heuvelhof, 1995; Hodges, 1986). Those different roles are crystallized in binding regulation, coregulation, or self-regulation processes (Puppis, 2010). A fourth, hybrid type of regulation is characterized by the presence of independent authorities (Price et al., 2015).

c. Instruments used to ensure media accountability, for example, obligations and constraints (Bardoel \& d'Haenens, 2004; Eberwein et al., 2018; Fengler et al., 2014), as well as "any non-State means of making media responsible towards the public" (Bertrand, 2000, p. 108). In this respect, the move toward the digital media era has provoked many questions regarding for the techniques to monitor the media and the instruments able to respond to the fast-changing nature of digital media (Babcock, 2012; Heikkilä et al., 2012). The public is frequently involved in collaborating with newsrooms to ensure accountability (Fengler et al., 2011).

Focusing on these factors, we synthesized four ideal types of media accountability models in European countries, ranging from the most State-centered to the most market-centered.

The first model is characterized by strong legislative and/or government intervention in the field of media regulation. The guiding principle is the maintenance of public control over private companies, largely translated into obligations of transparency about the property, production, and financing of such companies. The law sets obligations and constraints for media players. The countries that most resemble this model are France and Germany.

The second model also relies on the regulation of public institutions, but unlike the first, an ad hoc independent authority separate from both government and parliament is in charge. This authority typically has limited regulatory abilities but strong monitoring and sanctioning powers, as in Italy. The focus of legislation is on ensuring transparency in the relationships between media outlets and political parties to preserve a pluralistic regime. Eastern European countries such as the Czech Republic may also fall into this model, as they experienced the liberalization of the media during the 1990s and established regulatory authorities to monitor that process. However, due to increasing political parallelism and the concentration of the media market, professional accountability instruments are limited. It is no coincidence that some scholars have argued for the "Italianization" of the Czech media system (Eberwein et al., 2018; Splichal, 1994) to explain the increasing resemblance of Mediterranean and Eastern European countries in terms of media regulation and markets.

The third model involves the coregulation of the activities of media companies and nongovernmental organizations (i.e., audience protection groups). Typically, pluralist media outlets aim to increase representation of ethnic minorities and political opinions (such as in Belgium and the Netherlands). The role of the ombudsman, as well as other forms of internal audits, is well established in such media systems as an example of media responsiveness in a predigital era. Independent authorities monitor pluralism 
and responsiveness but normally do not have regulatory or sanctioning powers. The output of the coregulation model is visible in codes of ethical standards and codes of best practices defined by media professionals together with public authorities. For instance, in the United Kingdom, while all media (particularly public service broadcasters) are subject to the control of Ofcom, these guidelines were set in accordance with media players and journalists.

The fourth model is focused on freedom of information from the interference of the State and on the direct responsiveness of media outlets to their publics. It is often defined as a form of regulated self-regulation (as opposed to pure self-regulating systems like that in the United States), stressing that in European countries basic legislation is always put in place. This model is rooted in the historical tradition of Scandinavian countries like Sweden. Self-regulation has also developed in countries which experienced an authoritarian regime - such as Latvia, Lithuania, and Finlandthat later underwent a process of liberalization of the media. All the countries in this model share a vision of culture and communication as "epistemic commons" (Nieminen, 2014). The so-called "Nordic Media Welfare State" is characterized by the presence of an independent public service broadcaster and a system of public subsidies to the press (Syvertsen et al., 2014), combined with high competition among media outlets that favors the growth of self-imposed codes of journalistic conduct.

\section{Information Disorders and the Shift to Social Platforms' Accountability}

Information disorders represent one of the most serious challenges to journalism and to the relationship between media and democracy (Benkler et al., 2018; Wardle \& Derakhshan, 2017). Disinformation is false information created with the intent of harming the reputation of a person, organization, or country. While disinformation is not a digitally native phenomenon, it has reached an unprecedented intensity in the digital era.

In this context, policy makers have regulated not only the responsibilities of journalists and political parties in these processes but also those of social platforms (JonesJang et al., 2019). When confronted with the issues of fake news and disinformation, in particular, regulators have begun to increase the number of instruments to ensure media accountability (Eberwein et al., 2019) also including: algorithmic decisionmaking; crowdsourced reporting and/or fact-checking; and audiences' media literacy (Jones-Jang et al., 2019). These mechanisms, as suggested, can rely on technological or human components or a blend of the two.

There is a lack of research on how different European models of media accountability have adapted to this evolving context, excluding some noteworthy but descriptive attempts (Bayer et al., 2019; Global Legal Research Directorate, 2019). For this reason, we selected 11 European countries that are engaged in the restructuring of SPA: Belgium, the Czech Republic, Finland, France, Germany, Italy, Latvia, Lithuania, the Netherlands, Sweden, and the United Kingdom. This study aims at observing the extent to which media accountability models consolidated in a predigital era have survived and contributed to shaping social platform accountability models. We take a 
neo-institutionalist approach and, in particular, an approach that combines historical and constructivist institutionalism (Bannerman \& Haggart, 2015; Hay, 2008; Schmidt, 2008, 2010, 2012). In this view, institutions (such as accountability institutions, norms, and praxis observed here) do not emerge in a vacuum, but instead follow historically and contextually specific patterns that depend on the cultural, political, and economic particularities of each country. In other words, the aim of this article is to answer two research questions:

Research Question 1: Observing how different European countries have addressed social platforms' accountability, to what extent each country has shifted from its previous media accountability model toward another?

We expect to observe two competing patterns of fragmentation or convergence. If European countries continue to have different approaches to media accountability, the first pattern (fragmentation) would be observed. It means that the legacy of previous media accountability models is still active and the main driver for the consolidation of SPA models. On the contrary, we expect that the second pattern (convergence) can be observed if accountability models are similar to one another, meaning that European countries are converging on a specific and common answer to the problems related to SPA; if this is the case, SPA turns out to be independent and irrespective from previous media accountability models (i.e., less context-specific), thus highlighting the role of the technical and political features of social platforms in determining policy responses. Two considerations derive from the answer to Research Question 1, each focusing on the causes and the consequences of fragmentation/convergence. The first regards the role of technology in promoting a change in media policies. A convergence in European SPA models would suggest that technological developments in the media industry are levelling historically consolidated policy backgrounds; on the contrary, if a fragmentation is still observable, this technologically determinist hypothesis must be rejected. The second consideration surrounding Research Question 1 is about the possible consequences of fragmentation/convergence on the elaboration of a common framework of SPA inside the European Union institutions. In this respect, a convergence would parallel a more integrated EU response to the problems of social platforms' regulation, whereas a fragmentation would likely jeopardize such an integration. With reference to the role of technology in promoting policy change, we also observe how technological instruments are used to promote SPA. While the principles and the actors can be the same as in the predigital era, SPA is connected to a greater reliance on technological instruments, such as algorithms of detection, early alerts and mechanisms favoring crowdsourced reporting. That is why the article is going to answer the second research question:

Research Question 2: To what extent each model of social platforms' accountability is relying on technological instruments?

As an essential component of social platforms, technology may serve different policy purposes according to the varying contexts. We thus expect to find different degrees of reliance on technology in all models. 


\section{Methodology}

This article makes a comparative analysis of all pieces of legislation, strategies, and policy papers related to disinformation, fake news, and political propaganda, as they represent the most recent and attention-grabbing policy issues in the field of SPA. Our corpus was composed of 18 documents (two per country, except for Belgium, the Czech Republic, Germany, and Lithuania; see Table 1). All documents were retrieved from the official websites of governments and ministries involved in the regulation of social platforms and were published in a language spoken by the authors (French, English, or Italian).

To answer Research Question 1 and observe each country's shift, whether in the sense of convergence or fragmentation, we compared the position of a given country in the typology of social platform accountability models (as resulted from our analysis of policy documents) with the position of the same country in the typology of media accountability models (as indicated by the literature). The factors used to trace the typology of media accountability models were used to retrieve the models of SPA: the goals and principles used to guide the policies, the roles of all actors involved in solving the problem and the instruments used to enforce SPA. The analysis of instruments also served to provide an answer to Research Question 2.

Policy documents were scrutinized using a content analysis technique (i.e., counting code frequencies), which was blended with more qualitative approaches (Hajer, 2002; Hajer \& Wagenaar, 2003; Jones et al., 2014; Krippendorff, 2013; Rothmayr Allison \& Engeli, 2014). This model of policy analysis has been used in several previous studies (De Blasio, 2018; De Blasio \& Selva, 2016; De Blasio \& Sorice, 2016). Here, we coded segments corresponding to three items:

1. The principles and values used to motivate the policy, measured along the axes of control/freedom of information and transparency/responsiveness. Principles were coded by two coders following an interpretive approach ( $\alpha$ coefficient of agreement $=.95) .{ }^{1}$ Multiple codes can appear in the documents but the frequency of each code indicates its importance overall.

2. The policy network of actors, distinguishing among promoters of the policy, principal actors, allies, and opponents. In this case, paragraphs indicating the name of the actors and the corresponding functions/duties were coded.

3. The division of policy instruments between technological and human, indicated by a simple frequency count for each type of instrument retrieved in the documents (i.e., how many times an instrument appears in each document). We first coded the type of instrument in a binary logic (either technical or human, thus the sum of the two is $100 \%$ ); then we coded the specific kinds of instrument retrieved in the documents, in a bottom-up logic (thus the sum of all technical and human instruments, taken separately, is $100 \%$ each). 


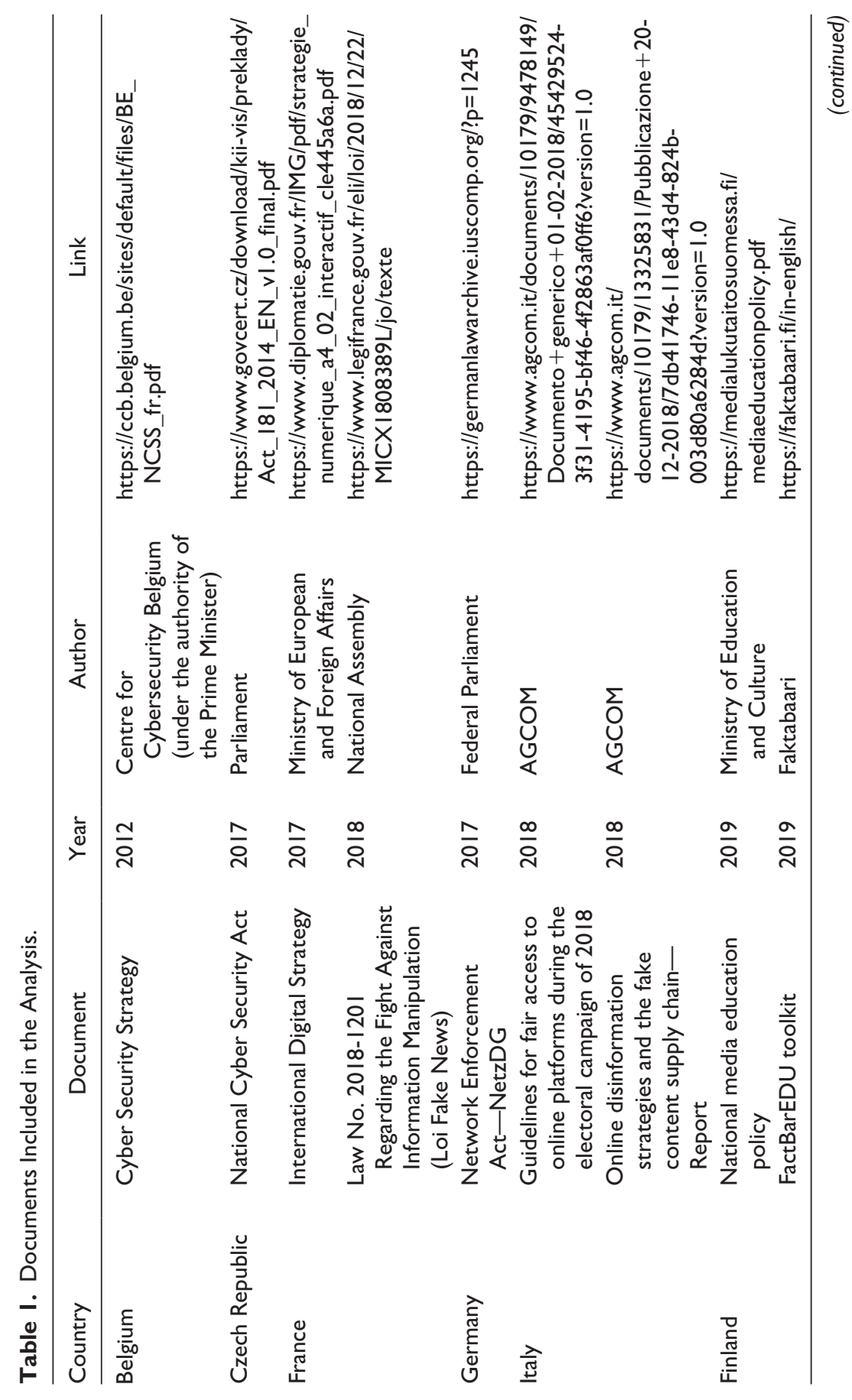




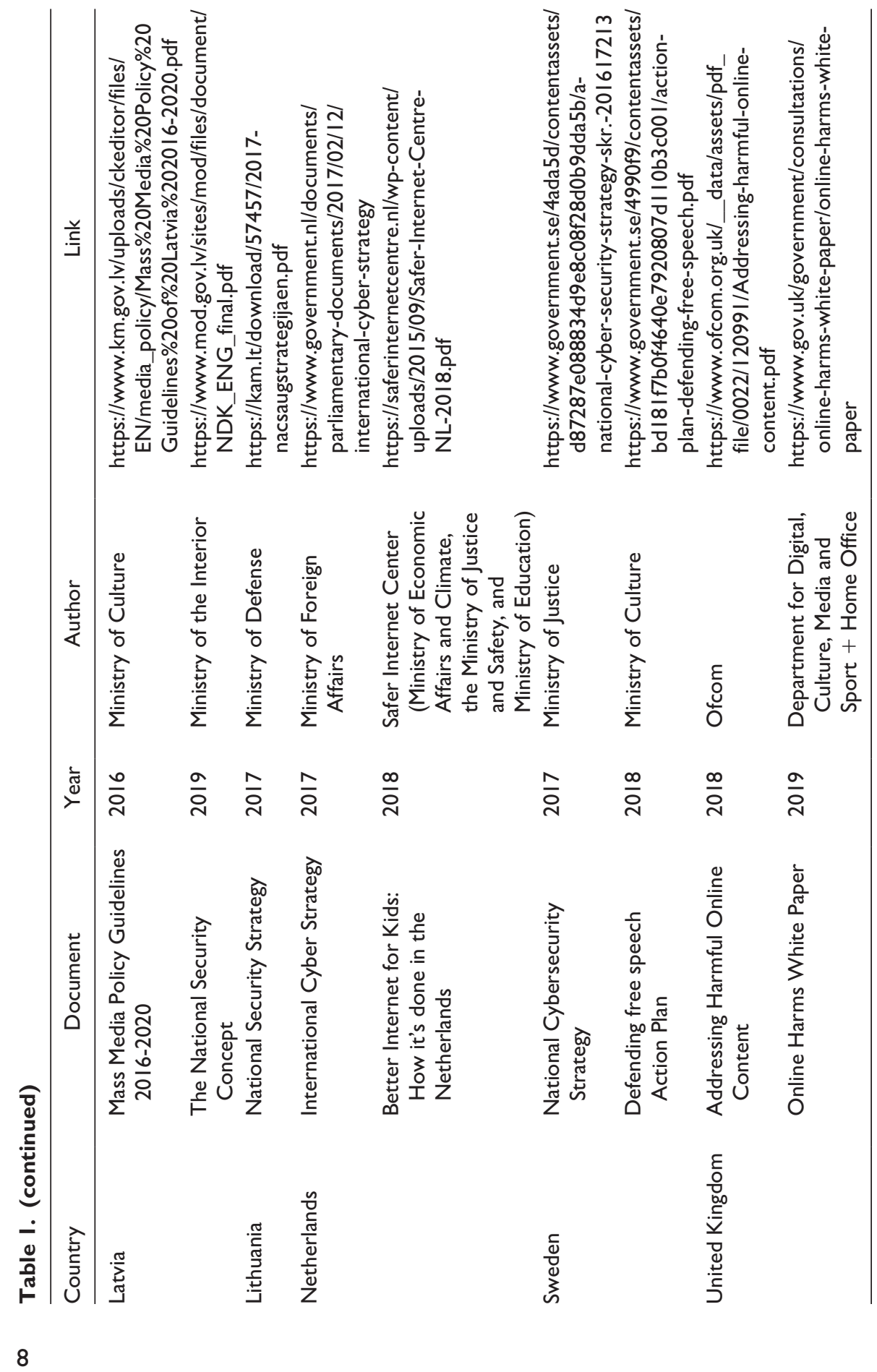




\section{Social Platform Accountability in Europe}

Answering to Research Question 1, the results of our analysis show that the models of media accountability have survived in the digital era, meaning that a fragmented framework is still present in Europe (Table 2).

Differences from previous models are marked with asterisks. A downward arrow indicates that the country has decreased its level of State control over social platform accountability in comparison with legacy media accountability; this change occurred only in the Czech Republic and Italy. In the Czech Republic, the principle of freedom of information/freedom of market is now guiding, but most of all the principle of transparency has been replaced with responsiveness. As it will be discussed in the next sections, no regulation is provided over social platforms; hence, they are not bound to transparency obligations. In Italy, while the overall principles have remained constant, SPA rests on different instruments than the law, for example, multistakeholder fora and codes of practice, that were not used in regulating legacy media. Code frequencies are indicated in parentheses and are calculated in reference to the total of the factor (principles or instruments) for each country.

\section{Model I: Platform Accountability Set by Law}

This model is characterized by a prevalence of State control and transparency, a strong role of the public sector, and the use of binding instruments that combine human and technological resources. In France and Germany, transparency ties ensure that public institutions (governments and parliaments) can monitor the extent to which social platforms protect the integrity of public debate. State control is justified based on the principle of electoral integrity, which is pursued at the expense of freedom of expression. In the shift from legacy to digital media, both countries have created a set of measures to tackle disinformation and hostile propaganda, mainly in the wake of their general elections and the rise of far-right rhetoric in the public sphere.

The Network Enforcement Act passed the German Federal Parliament in June 2017. The most binding part of this law assigns responsibility to social platforms for illegal content hosted on them, imposing a "notice and takedown" mechanism that instructs platforms to remove illegal content and hate speech within 24 hours of publication. This provision has elicited a great deal of criticism (Heldt, 2019; Knodt \& Echikson, 2018; Tworek \& Leersen, 2019), as it "privatizes" control over the illegality of content without considering that platforms can easily shift toward precautionary censorship if they do not have the time, resources, and expertise to guarantee compliance with the law. In addition, platform operators must send a yearly report describing the actions they have taken to tackle illegal content (\$2), establish an easy and accessible tool for encouraging crowdsourced user reports $(\$ 3)$ and pay fines if they do not fulfil those provisions $(\$ 4)$.

In late 2018, France promulgated a law that specifically punishes the publication and dissemination of fake news during electoral periods (Organic Law No. 2018-1201 of 22 December 2018 Regarding the Fight Against Information Manipulation). This 


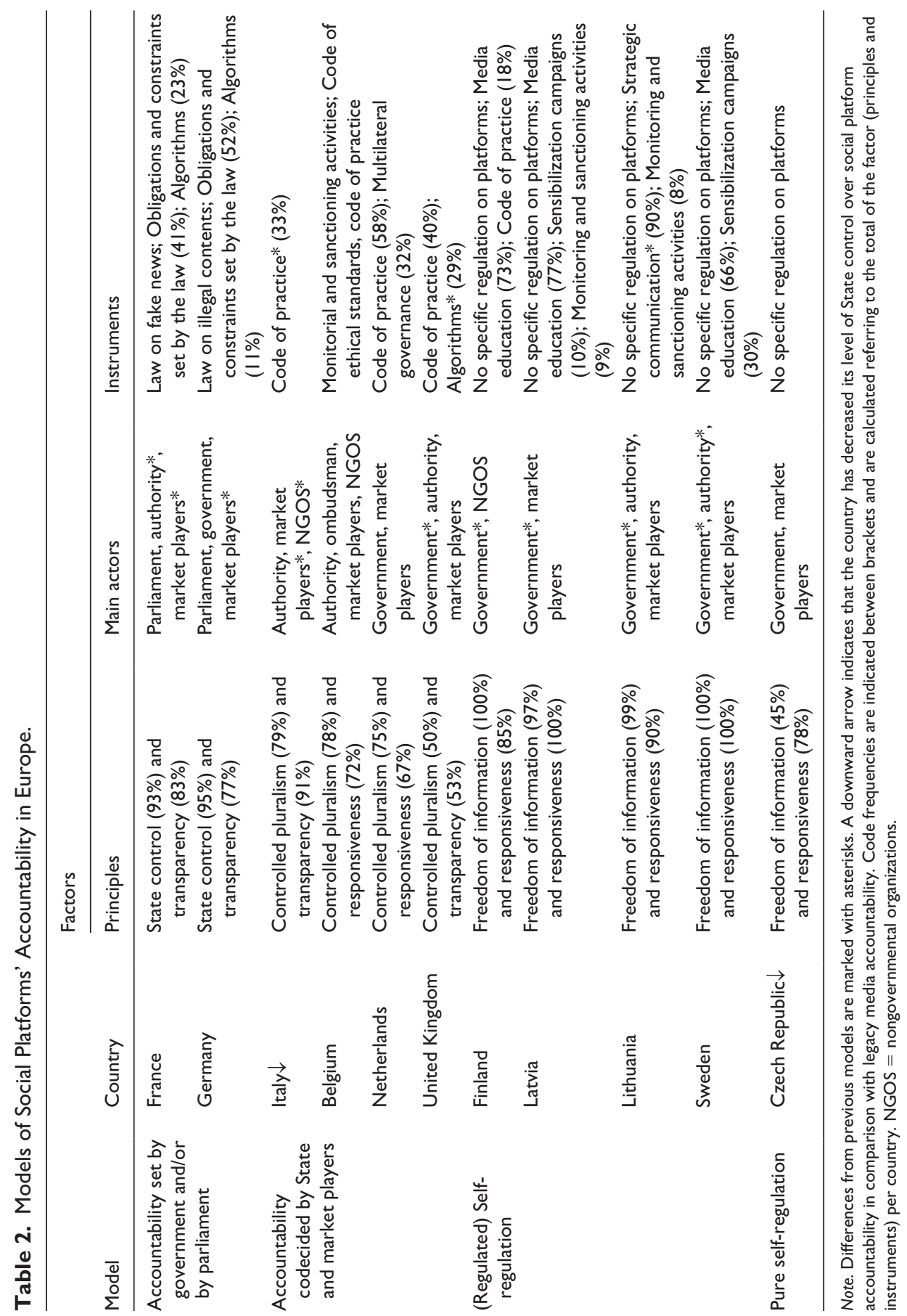


law reinforced some of the provisions of the preexisting norms regarding fake news. It also requires social platforms to maintain control over fake accounts and bots; privilege content created by certified journalistic sources through recommendation and search algorithms; encourage forms of crowdsourced reporting of suspicious content; and, most of all, implement tools for the rapid detection and removal of illegal content. The most important innovation of the French fake news law is its introduction of a set of obligations and constraints for social platform operators: the obligation to be transparent regarding the source of financing for political advertising (the so-called "paid for by" mechanism), the use of personal data and the amount of money paid for diffusing ads. The law also applies the principle of precaution in establishing judicial enforcement in the case of reported disinformation: if a person, political group or party reports a case of disinformation or fake news, the judge can impose "any proportional and necessary measure," including the removal of the suspicious content, to prevent its distribution. This is also a "notice and takedown" regime; however, in this case, it is enforced by judicial intervention as a safeguard for freedom of expression, on the one hand, and efficacy, on the other.

Manipulation of information is also inscribed as a matter of foreign policy. In this respect, this model resembles those of the Baltic countries. The German government is currently planning to revise its 2011 Cyber Security Strategy; in the meantime, it has created the Federal Office for Information Security to coordinate police training efforts, military-communicative strategy, and cybersecurity enforcement. The French government, meanwhile, published its International Digital Strategy in 2017, in which principles of multistakeholderism and open governance are cited in an effort to hold social platforms responsible for national security:

Hold digital actors responsible in the fight against disinformation [through]:- report and removal of fake news as quickly as possible by platforms [ . . ];--mobilization of platforms through the development of auto- and co-regulation;-- vigilance by platforms over problematic sources. (French International Digital Strategy, p. 12 [author's translation]).

Germany has followed the same path in partnering with platforms to implement online security policies. This marks a discontinuity with the regulatory practices that previously characterized media accountability in France and Germany and leaves the door open to further development.

\section{Model 2: Codeciding Accountability}

The second model-Accountability codecided - is inspired by principles of controlled pluralism (together with either transparency or responsiveness depending on the specific case), the involvement of the private sector and civil society in multistakeholder decision-making processes, and a preference for human instruments like the signature of a Code of Practice. Belgium, the Netherlands, and the United Kingdom have maintained their positions in this model. These countries blend the responsiveness demanded 
by legacy media (i.e., through obligations related to the public service media approach) with transparency surrounding political actors' behavior. Contrary to France and Germany, transparency is also set to safeguard freedom of expression on social platforms from the undue interference of public authorities.

These countries have directly addressed SPA by involving market players in discussing and codetermining strategy. Platforms and media in general are also involved in these countries' media literacy programs as partners. Parallel to governmental actions involving social platforms, initiatives to counter fake news and disinformation have mushroomed in civil society organizations and newsrooms.

Belgium published the first version of its Cyber Security Strategy in 2012, which led to the creation of the Centre for Cybersecurity under the authority of the Prime Minister. More recently, the Centre was also given the task of combating online disinformation. Together with the Belgian Federal Ministry of Finance and Digital Agenda, the Belgian federal government is proceeding in three directions: first, it has recruited academic and media experts to discuss the problem and draft policy recommendations; second, it has aimed to raise public awareness about disinformation by launching a consultation; and third, it has invested in many media education initiatives. Local governments are responsible for implementing media education.

Disinformation is one of the hybrid threats included in the Netherlands' International Cyber Strategy: this document focuses on the need to collaborate with social platforms, civil society, and other countries to reach the goal of securing the internet. More recently, the Dutch Ministry of the Interior announced a collaboration with social platforms to specifically address disinformation. In the field of media education, the Safer Internet Centre has coordinated joint efforts by the Ministries of Education and Economic Affairs since 2006 in partnership with Google and Facebook, among others. In 2018, it published a white paper titled "How it's done in the Netherlands" describing the initiatives undertaken, most of which involved social platforms, legacy media, experts, journalists, and schools.

In the United Kingdom, Ofcom suggested certain policy recommendations in 2018, including "appropriate levels of protection and assurance against harmful content and conduct" set by the parliament and "safeguarding of freedom of expression" (p. 27) through platform regulation that relies on adaptability over time, transparency commitments, power of enforcement and independence (p. 28). One year later, the government initiated a public consultation to draft the Online Harms White Paper, which outlined a new specific normative and a new independent authority to fight disinformation. Social platform operators are deeply involved in many initiatives to combat disinformation (e.g., media literacy and hackathons, workshops, policy briefings). What has changed is that regulators' interlocutors now include online players. The aim of this strategy is to overcome self-regulation and the main actor driving it is the government:

The absence of clear standards for what companies should do to tackle harms on their services makes it difficult for users to understand or uphold their rights. The government believes that voluntary efforts have not led to adequate or consistent steps to protect British citizens online. (Online Harms White Paper, paras 2.14 and 2.15) 
In pursuing this approach,

the government will establish a new statutory duty of care on relevant companies to take reasonable steps to keep their users safe and tackle illegal and harmful activity on their services. The fulfilment of this duty will be overseen and enforced by an independent regulator. (Online Harms White Paper, paras 3.1 and 3.2).

The Italian model of media accountability is characterized by the strong role of Italy's independent authority (AGCOM), which has been maintained in the fight against disinformation. At the same time, Italy has shifted toward a coregulation model of social platform accountability, as AGCOM is proceeding with a multistakeholder logic. Social platform operators are invited to join AGCOM in monitoring disinformation and developing a strategy to prevent it. As such, social platforms are conceived as allies in this fight; together with several nongovernmental organizations, they participated in a roundtable - "Pluralism and Platforms" - set up by AGCOM to examine the path forward. The authority has not been left completely alone in this task, as it has partnered with experts and market players, but has also not been supported by the Italian government (which was experiencing turbulence in the aftermath of the March 2018 elections) or parliament. This situation changed somewhat during the Covid-19 pandemic, when the "infodemic" has been regulated by a partnership between the Ministry of Health, Ministry of Education, and Prime Minister's Office and Google, Facebook, and WhatsApp. In the power vacuum that characterized Italy until March 2020, AGCOM published guidelines for political parties rallying for the 2018 elections, extending the legislation regarding the fair representation of political forces that was already applicable to legacy media to online platforms. However, this decision mainly addressed political parties and organizations, rather than platforms as editors.

\section{Models 3 and 4: Variants of Self-Regulation by Social Platforms}

The third and fourth models - respectively, Regulated self-regulation and Pure selfregulation - are featured by principles of freedom of information and responsiveness, and by the collaboration among government, market players, and civil society in micro initiatives of sensibilization and education. The Pure self-regulation model typically does not have a specific policy addressing the problem of disinformation in terms of SPA (but in issues of cyber-security and counterespionage, for instance). The most striking element is that market players are free to address or not the issues raised by information disorders. Within this group, we can still distinguish those who adopt a model of regulated self-regulation - in which platforms are free to intervene or not but must do so within the framework of governmental monitoring and law enforcement (Finland, Latvia, Lithuania, and Sweden) - from those who adopt a model of pure selfregulation (Czech Republic) in the sense that they have no specific provision for addressing online disinformation. Due to historical contingencies and recurrent cases of Russian interference, these countries all began fighting online disinformation in 2014 (shortly after the Crimea case) and have framed the fight against disinformation 
as a national security problem that can be solved using a number of instruments: for instance, strategic communication (as in Lithuania) or what the Swedes call "psychological defence" (European Integration Studies Centre, 2018; Rossbach, 2017). Disinformation is thus embedded in a context of information threats that undermine national security. The actions undertaken to tackle disinformation are all coherent with this military-communicative strategy, which is conducted in cooperation with international NATO allies (Atmante et al., 2019).

Identifying key policy documents for fighting disinformation is not an easy task. The policies regarding media freedom remain untouched: the principles have remained stable, favoring freedom of information and media responsiveness. All countries with these models can rely on high-quality journalism and vibrant civil societies that can sustain a regime of self-regulation and adherence to ethical standards, even during electoral periods. Media professionals have begun to implement many initiatives for fact-checking and debunking disinformation campaigns, such as Faktabaari in Finland (Heikkilä \& Väliverronen, 2019). In parallel, governmental efforts against disinformation have concentrated on reinforcing digital media literacy and favoring the work of responsive journalists. While relying on the same principles as the previous media accountability model (i.e., freedom of information and responsiveness), Latvia and Lithuania have left the task of dealing with controversies directly involving Russian-speaking media to the judiciary and the broadcasting media authority that were forced to close (see, e.g., European Commission, 2018; The Baltic Times, 2020).

In this sense, social platforms' responsibilities are highly restricted, given that attention is mainly focused on journalistic ethics and citizens' behaviors. Awareness campaigns and media literacy programs are the most common instruments in the countries falling into these models. As disinformation must be fought in the classroom, the main partners with governments include school teachers and nongovernmental organizations engaged in the development of specific toolkits, especially in Finland and Sweden.

The main difference from previous approaches to media accountability in these countries is the presence of the government as a main strategist. Finland has created an intergovernmental task force with the goal of monitoring and preventing fake news, anti-immigrant racism and hate speech, while Latvia and Lithuania reinforced the roles of the departments responsible for information security and strategic communication. Sweden assigned the responsibility of monitoring online disinformation to the Civil Contingency Agency (MSB), an independent body that provides periodic risk assessments; more recently, it has attempted to create a more specific authority to tackle online disinformation.

In the Czech Republic, the situation is quite different. There, the self-regulation of social platforms does not depend on a preexisting media accountability culture, as in the other four countries, but rather the opposite: due to the government's structural control of the media, conflicts of interest between broadcast media and politics, and more recent allegations that the far-right government collaborated directly with Russia, the Czech Republic's approach to disinformation is flawed (Janda \& Víchová, 2017). The main actions undertaken to fight disinformation in the Czech Republic have come from civil society organizations and journalists (for a synthetic overview through 
Table 3. Code Frequencies of Human Versus Technological Instruments in the Policies of all Models.

\begin{tabular}{|c|c|c|c|c|}
\hline & $\begin{array}{l}\text { Model I- } \\
\text { Accountability } \\
\text { by law }\end{array}$ & $\begin{array}{l}\text { Model 2- } \\
\text { Codecided } \\
\text { accountability }\end{array}$ & $\begin{array}{l}\text { Model 3- } \\
\text { Regulated self- } \\
\text { regulation }\end{array}$ & $\begin{array}{l}\text { Model } 4- \\
\text { Pure self- } \\
\text { regulation }\end{array}$ \\
\hline Human instruments & 77 & 82 & 100 & 100 \\
\hline Code of practice & 6 & 36 & 16 & 0 \\
\hline Extension of previous norms & 35 & 13 & 0 & 44 \\
\hline Media literacy and campaigns & 3 & 18 & 69 & 13 \\
\hline Monitoring & 2 & 12 & 0 & 39 \\
\hline Multilateral governance & 18 & 8 & 15 & 4 \\
\hline Obligations and constraints & 36 & 13 & 0 & 0 \\
\hline $\begin{array}{l}\text { Annual report by } \\
\text { operators }\end{array}$ & II & 5 & 0 & 0 \\
\hline Notice and takedown & 11 & I & 0 & 0 \\
\hline Paid for by & 12 & 7 & 0 & 0 \\
\hline Public register of financing & 2 & 0 & 0 & 0 \\
\hline Technological instruments & 23 & 18 & 0 & 0 \\
\hline $\begin{array}{l}\text { Algorithms of } \\
\text { recommendation of quality } \\
\text { contents }\end{array}$ & 20 & 33 & 0 & 0 \\
\hline $\begin{array}{l}\text { Control of fake accounts and } \\
\text { bots }\end{array}$ & 20 & 27 & 0 & 0 \\
\hline Crowdsourced reporting & 20 & 8 & 0 & 0 \\
\hline Rapid detection and removal & 40 & 7 & 0 & 0 \\
\hline Safety technologies & 0 & 25 & 0 & 0 \\
\hline
\end{tabular}

Note. Code frequencies of the human and technological instruments used in each model are indicated in bold.

2017, see Kremlin Watch, 2017). In 2017, before the current government was elected, the National Cyber Security Act enhanced the tasks and resources of the National Cyber and Information Security Agency (NÚKIB). The case of the Czech Republic illustrates another variant of the fight against disinformation. In this context, disinformation is not just a matter of information spreading through media and social platforms, but a problem linked to the unending and overwhelming presence of Russian spies on Czech soil. The public debate is thus polluted by disinformation campaigns that originate in popular culture, ordinary conversations, and everyday interactions as much as on social platforms.

\section{Algorithms for Social Platforms' Accountability}

Answering Research Question 2, Table 3 documents the code frequencies of the human and technological instruments used in each model (indicated in bold). All models show a preference for human over technological instruments, ranging from $77 \%$ in 
France and Germany to $100 \%$ in the countries falling into Models 3 and 4 . Within the category of human instruments, we identified preferences for obligations and constraints in Model 1 (36\%); the elaboration of codes of practice for social platform operators in Model 2 (36\%); media literacy programs and awareness campaigns in Model 3 (69\%); and the expansion of existing norms in Model 4 (44\%).

The preference for human instruments could be explained as an output of the regime of coregulation, which is now expanding to most countries. As market players collaborate with public authorities to design antidisinformation strategies, they are likely more amenable to solutions that minimize the risk of regulations addressing the functioning of their algorithms and content management. In part, the avoidance of technological instruments is also due to the nonbinding nature of the policy documents (excepting the French and German laws). However, it mainly derives from the fact that data, content, and the algorithms for their management on social platforms are industry assets. Nevertheless, it must be acknowledged that public policies are encouraging social platforms to undertake any technological measure that they want to and can develop to block disinformation, leaving market operators free to choose among the more viable options.

Models 1 and 2 are more explicit (and binding) in terms of the technological requirements to fight disinformation compared with the other two models: in effect, Model 1 relies on a quota of $23 \%$ of technological instruments and Model 2 on $18 \%$. The countries in Models 3 and 4 leave social platforms, as well as any other media player, free to do what they deem necessary to ensure freedom of information and maintain a relationship of trust with users. Belgium, France, Germany, Italy, Sweden, and the United Kingdom use algorithms of recommendation to privilege journalistic sources and accurately control fake accounts and bots. The U.K. White Paper speaks generically about "safety technologies," likely not with the aim of binding social platforms to specific settings but to underline the necessity of ensuring a safe environment for users. At the same time, the United Kingdom is explicit in its recommendation of journalistic content, easier crowdsourced reporting mechanisms and rapid detection and removal of suspicious content.

Given these differences in technological instruments, European models of social platform accountability vary significantly in their reliance on algorithms.

\section{Conclusions}

Social platform accountability models in Europe are the result of both fragmenting and converging trends. The attempt to answer to Research Question 1 has shown that the legacy of media accountability models is still strong, as it is visible in the principles that guide countries' policies on disinformation: in particular, in the position taken by each country on the conflict between State control and freedom of information, but also between State control and market freedom. In other words, the cultural roots of SPA are derived from preexisting ideological conflicts that have found a tentative equilibrium in media regulations, and such cultural roots continue to exercise an influence. 
Some changes are observable in the convergence of all models toward the involvement of market players as allies in the fight against disinformation. Governments play a primary role in developing strategies to combat disinformation, particularly in countries that experience a securitization of perspectives on disinformation. From an endogenous problem of media involving the quality of journalistic practice and the critical skills of citizens (as the definition of the term "information disorder" would suggest), disinformation has come to be viewed a matter of national security in the sense of an exogenous threat coming from foreign countries. However, we expect that as soon as the perception of danger and moral panic surrounding disinformation pass, the self-regulating model will proceed at full speed.

The focus on policy instruments to answer to Research Question 2 highlighted a difference in how the countries in this study approach combating disinformation, depending on the control exercised by public authorities over social platforms: where policies are more binding (as in France and Germany) - and partly in the codecided accountability model, as well — technological tools are better specified. Paradoxically, the most binding interventions aim to secure SPA but are also inherently limited: given the importance that the laws assign to technological instruments, the provisions are subject to rapid obsolescence. The U.K. White Paper, for instance, suggests taking a "regulation by principles" approach, which can be translated as the provision of a set of guiding principles and objectives that can be implemented widely in accordance with technological development.

On the contrary, where a regime of self-regulation is in place, technological tools are the prerogative of market operators. This peculiar configuration of social platform accountability imposes a gap between countries who have and countries who do not have access to resources, data, and tools to enforce social platforms' establishment of any necessary measures to fight disinformation. Moreover, it delimits the perimeter of SPA, as the platforms decide for what they will be accountable and neither the State nor the public has the tools to control this decision.

The models of codecided and self-attributed accountability aim for continuous revision, thanks to the collaboration between authorities and social platforms. They have the limitation of being extremely ephemeral, as SPA is defined by market operators based on what they are already doing to fight disinformation. The models of codecision and self-regulation have a broader view of the problem, which is noticeable in the instruments they adopt: media literacy programs, awareness campaigns, information security strategies, and so on. The responsibility for disinformation is thus distributed among different social groups (i.e., citizens, journalists, public officials, and police). The difference between coregulation and self-regulation, however, is that the latter is a long-term strategy that can be fragile in the short term: self-regulating systems rely fully on the construction of social and democratic antibodies to disinformation, but this can be achieved only if journalism, civil society, and politics collaborate. If even one of these actors takes a step back, the balance is compromised, and the result is the dilution of the model of regulation by independent authorities who can act only in a regulated political and legislative context. Where this context is nonexistent, as in Italy and the Czech Republic, this model is dispersed. In Italy, the authority still maintains 
a pivotal role in media regulation but is not legitimized by an adequate legislative framework addressing SPA; Italy now resembles Latvia and Lithuania much more than France and Germany. In the case of the Czech Republic, disinformation is not a matter of the media-regulating authority's competence, and the battle against fake news is fought through intelligence strategies. On the contrary, the U.K. White Paper points to the creation of a regulatory authority to fight disinformation.

At the same time, some elements support the convergence of those models toward an as-yet embryonic but nonetheless influential model of coregulation:

a. The weakening of State control in favor of freedom of information.

b. Enhanced transparency in social platforms' politics-related activities as a guiding principle for ensuring public monitoring. At the same time, in the interest of citizens and social platforms, transparency ensures that the State is not applying censorship.

c. The standardization of a multistakeholder model of coregulation characterized by the increasing involvement of social platform operators and nongovernmental organizations in monitoring and removing harmful content and in defining codes of practice and technological instruments for addressing disinformation.

In fact, these are the main features of the European Union's approach toward SPA, exemplified by the Code of Practice drafted with and signed by market operators. The convergence toward a common framework of SPA is thus observable not only at the supranational level (i.e., in the European Union's institutions and regulations) but also at the national level (i.e., national models), and such a convergence is driven by ideological and social factors (principles and main actors), much more than by technological ones. None of the elements listed above has a technological nature, thus inducing to strongly reject a technologically determinist approach to policy change. The fragmentation observed in the use of technological instruments (Research Question 2) also reinforce this argument: when technology is applied to policy making, it produces fragmentation much more than convergence.

In this way, SPA in Europe is caught between tradition and innovation. Our study highlights the weight and influence of historical and cultural elements in defining not only who is held responsible for disinformation but also how different national societies frame the relationships between State and market, freedom of information and security, and ultimately digital media and democracy.

\section{Declaration of Conflicting Interests}

The author(s) declared no potential conflicts of interest with respect to the research, authorship, and/or publication of this article.

\section{Funding}

The author(s) received no financial support for the research, authorship, and/or publication of this article. 


\section{Note}

1. The list of keywords used for coding is the following:

- Control: State control, public control, monitoring;

- Pluralism: pluralism, public service media, plurality, viewpoints, fairness;

- Freedom of information: freedom of information, freedom of speech, right to be informed, civic control;

- Transparency: transparency, accountability, open data;

- Responsiveness: responsiveness, responsibility, relationship with the public.

Although keywords have been used as proxies for the principles, the authors acknowledge that the process of coding has followed an inherently interpretive approach: whether keywords were found in the sentences, the coders have read them in contrast with the wider paragraphs and sections of the documents. This procedure is motivated by the fact that the meaning of concepts can oscillate across different cultural contexts and political leanings. For instance, the terms "pluralism" and "accountability" can be used with different meanings and even disfigured in authoritarian contexts (which is not the case for any of the countries covered in this study). On the cultural variance of the term pluralism and related concepts in media studies we recommend the reading of Valcke et al. (2015), and De Blasio and Sorice (2014).

\section{References}

Atmante, K., Kaljurand, R., \& Jermalavicius, T. (2019). Strategic culture of the Baltic States: The impact of Russia's new wars. In K. Miklossy \& H. Smith (Eds.), Strategic culture in Russia's neighborhood: Change and continuity in an in-between space (pp. 53-82). Lexington Books.

Babcock, W. A. (Ed.). (2012). Media accountability: Who will watch the watchdog in the Twitter age? Routledge.

Bannerman, S., \& Haggart, B. (2015). Historical institutionalism in communication studies. Communication Theory, 25(1), 1-22. https://doi.org/10.1111/comt.12051

Bardoel, J., \& d'Haenens, L. (2004). Media responsibility and accountability: New conceptualizations and practices. Communications, 29(1), 5-25. https://doi.org/10.1515/ comm.2004.007

Bayer, J., Bitiukova, N., Bard, P., Szakács, J., Alemanno, A., \& Uszkiewicz, E. (2019). Disinformation and propaganda: Impact on the functioning of the rule of law in the EU and its member states. SSRN Electronic Journal. https://doi.org/10.2139/ssrn.3409279

Benkler, Y., Faris, R., \& Roberts, H. (2018). Network propaganda: Manipulation, disinformation, and radicalization in American politics. Oxford University Press.

Bertrand, C. J. (2000). Media ethics and accountability systems. Transaction Publishers.

Bruijn, J. A., \& Heuvelhof, E. F. (1995). Policy networks and governance. In D. L. Weimer (Ed.), Institutional design (pp. 161-179). Springer. https://doi.org/10.1007/978-94-0110641-2_8

Christians, C. G., Glasser, T., McQuail, D., Nordenstreng, K., \& White, R. A. (Eds.). (2009). Normative theories of the media: Journalism in democratic societies. University of Illinois Press.

De Blasio, E. (2018). Il governo online: Nuove frontiere della politica [The online government: New frontiers of politics]. Carocci. 
De Blasio, E., \& Selva, D. (2016). Why choose open government? Motivations for the adoption of open government policies in four European countries. Policy \& Internet, 8(3), 225-247. https://doi.org/10.1002/poi3.118

De Blasio, E., \& Sorice, M. (Eds.). (2014). Il servizio pubblico: Pluralismo, democrazia, media [Public service: Pluralism, democracy, media]. http://www.sussidiarieta.net/files/file/rapportoServizioPubblico.pdf

De Blasio, E., \& Sorice, M. (2016). Open government: A tool for democracy? Medijske Studije, 7(14), 14-31. https://doi.org/10.20901/ms.7.14.3

Donders, K. (2012). Public service media and policy in Europe. Palgrave Macmillan.

Eberwein, T., Fengler, S., \& Karmasin, M. (Eds.). (2018). European handbook of media accountability. Routledge.

Eberwein, T., Fengler, S., \& Karmasin, M. (Eds.). (2019). Media accountability in the era of post-truth politics: European challenges and perspectives. Routledge.

Eberwein, T., Fengler, S., Lauk, E., \& Leppik-Bork, T. (Eds.). (2011). Mapping media accountability: In Europe and beyond. Herbert von Halem Verlag.

European Commission. (2018). Commission Decision of 4.5.2018 on the compatibility of the measures adopted by Lithuania pursuant to Article 3 (2) of Directive 2010/13/EU. European Union.

European Integration Studies Centre. (2018). Lithuanian-Swedish roundtable expert discussions on social resilience and psychological defence. http://www.eisc.lt/uploads/documents/files/ EISC_policy\%20brief(1).pdf

Fengler, S., Eberwein, T., \& Leppik-Bork, T. (2011). Mapping media accountability - In Europe and beyond. In T. Eberwein, S. Fengler, E. Lauk, \& T. Leppik-Bork (Eds.), Mapping media accountability - In Europe and beyond (pp. 7-21). Herbert von Halem Verlag. http://www. halem-verlag.de/wp-content/uploads/2011/05/9783869620381_lese.pdf

Fengler, S., Eberwein, T., Mazzoleni, G., \& Porlezza, C. (Eds.). (2014). Journalists and media accountability. Peter Lang.

Global Legal Research Directorate. (2019). Initiatives to counter fake news in selected countries. https://www.loc.gov/law/help/fake-news/counter-fake-news.pdf

Hajer, M. (2002). Discourse analysis and the study of policy making. European Political Science, 2(1), 61-65. https://doi.org/10.1057/eps.2002.49

Hajer, M. A., \& Wagenaar, H. (Eds.). (2003). Deliberative policy analysis: Understanding governance in the network society. Cambridge University Press.

Hallin, D. C., \& Mancini, P. (2004). Comparing media systems: Three models of media and politics. Cambridge University Press.

Hay, C. (2008). Constructivist institutionalism. In S. A. Binder, R. A. W. Rhodes, \& B. A. Rockman (Eds.), The Oxford handbook of political institutions. Oxford University Press. https://doi.org/10.1093/oxfordhb/9780199548460.003.0004.

Heikkilä, H., Domingo, D., Pies, J., Glowacki, M., Kus, M., \& Baisnée, O. (2012). Media Accountability goes online: A transnational study on emerging practices and innovations (MediAcT Working Paper No.14). http://www.mediaact.eu/fileadmin/user_upload/WP4 Outcomes/WP4_Report.pdf

Heikkilä, H., \& Väliverronen, J. (2019). Media accountability in the era of fake news: Journalistic boundary work and its problems in Finland. In T. Eberwein, S. Fengler, \& M. Karmasin (Eds.), Media accountability in the era of post-truth politics: European challenges and perspectives (pp. 55-68). Routledge.

Heldt, A. (2019). Reading between the lines and the numbers: An analysis of the first NetzDG reports. Internet Policy Review, 8(2). https://doi.org/10.14763/2019.2.1398 
Hodges, L. (1986). Defining press responsibility: A functional approach. In D. Elliott (Ed.), Responsible journalism (pp. 13-31). Sage.

Janda, J., \& Víchová, V. (2017). The Kremlin's hostile influence in the Czech Republic: The state of play. In The Warsaw Institute Review (pp. 25-33). https://www.kremlinwatch.eu/userfiles/the-kremlin-s-hostile-influence-in-the-czech-republic-the-state-ofplay_15273212723437.pdf

Jones, M. D., Shanahan, E. A., \& McBeth, M. K. (Eds.). (2014). The science of stories: Applications of the narrative policy framework in public policy analysis. Palgrave Macmillan.

Jones-Jang, S. M., Mortensen, T., \& Liu, J. (2019). Does media literacy help identification of fake news? Information literacy helps, but other literacies don't. American Behavioral Scientist, 65(2), 371-388. https://doi.org/10.1177/0002764219869406

Knodt, O., \& Echikson, W. (2018). Germany's NetzDG: A key test for combatting online hate. CEPS Working Paper, 2018/09. http://wp.ceps.eu/wp-content/uploads/2018/11/RR\%20 No2018-09_Germany's\%20NetzDG.pdf

Krippendorff, K. (2013). Content analysis: An introduction to its methodology (3rd ed.). Sage.

Lowe, G. F. (Ed.). (2009). The public in public service media. Nordicom.

McQuail, D. (2005). McQuail's mass communication theory (5th ed.). SAGE.

Morlino, L. (2012). Changes for democracy: Actors, structures, processes. Oxford University Press.

Nieminen, H. (2014). A short history of the epistemic commons: Critical intellectuals, Europe and the small nations. Javnost-The Public, 21(3), 55-76. https://doi.org/10.1080/131832 22.2014.11073413

Price, M. E., Verhulst, S., \& Morgan, L. (2015). Routledge handbook of media law. Routledge.

Puppis, M. (2010). Media governance: A new concept for the analysis of media policy and regulation. Communication, Culture \& Critique, 3(2), 134-149. https://doi.org/10.1111/j.17539137.2010.01063.x

Rossbach, N. (2017). Psychological defence: Vital for Sweden's defence capability. https:// www.foi.se/rest-api/report/FOI\%20MEMO\%206207

Rothmayr Allison, C., \& Engeli, I. (2014). Comparative policy studies conceptual and methodological challenges. Palgrave Macmillan.

Schmidt, V. A. (2008). Discursive institutionalism: The explanatory power of ideas and discourse. Annual Review of Political Science, 11(1), 303-326. https://doi.org/10.1146/ annurev.polisci.11.060606.135342

Schmidt, V. A. (2010). Taking ideas and discourse seriously: Explaining change through discursive institutionalism as the fourth "New Institutionalism." European Political Science Review, 2(1), 1-25. https://doi.org/10.1017/S175577390999021X

Schmidt, V. A. (2012). The state and political economic change: Beyond rational choice and historical institutionalism to discursive institutionalism. In M. Telò (Ed.), State, globalization and multilateralism: The challenges of institutionalizing regionalism (pp. 99-118). Springer.

Siebert, F. S., Peterson, T., \& Schramm, W. (1963). Four theories of the press: The authoritarian, libertarian, social responsibility, and soviet communist concepts of what the press should be and do. University of Illinois Press.

Splichal, S. (1994). Media beyond socialism: Theory and practice in East-Central Europe. Westview Press.

Syvertsen, T., Enli, G., Mjos, O. J., \& Moe, H. (2014). The media welfare state: Nordic media in the digital era. University of Michigan Press. 
The Baltic Times. (2020). Court upholds ban on nine Russian television channels in Latvia. February 7, 2020. https://www.baltictimes.com/court_upholds_ban_on_nine_russian_television_channels_in_latvia/

Tworek, H., \& Leersen, P. (2019). An Analysis of Germany's NetzDG Law. Transatlantic High Level Working Group. https://www.ivir.nl/publicaties/download/NetzDG_Tworek_ Leerssen_April_2019.pdf

Valcke, P., Sükösd, M., \& Picard, R. G. (Eds.). (2015). Media pluralism and diversity. Palgrave global media policy and business. Palgrave Macmillan. https://doi.org/10.1057 /9781137304308_1

Wardle, C., \& Derakhshan, H. (2017). Information disorder: Toward an interdisciplinary framework for research and policymaking. https://rm.coe.int/information-disorder-towardan-interdisciplinary-framework-for-researc/168076277c

\section{Author Biographies}

Emiliana De Blasio is professor of Media Studies, Media Gender and Politics, and Open Government at LUISS University. She is the director of the executive programme in Politics \& Technology at the LUISS School of Government. Her work is focused on media and political participation, digital democracy and empowerment. She has recently edited a special issue of Media and Communication titled "The Ongoing Transformation of the Digital Public Sphere" (with M. Kneuer, W. Schunemann and M. Sorice).

Donatella Selva is postdoctoral fellow at Tuscia University, where she teaches Sociology. She is also assistant professor of Media Studies and Open Government at LUISS University. Her work focuses on the analysis of discourse surrounding the adoption of technology in governance processes. She has published about digital policies, platform analysis and political communication, among which the latest is the e-book "Digital Emotions". 